\title{
Successful Tracheal Occlusion Using Ultrathin Fetoscopic Equipment Combined with Real-Time Three-Dimensional Ultrasound
}

\author{
M. Tchirikov \\ Department of Obstetrics and Fetal Medicine, Johannes Gutenberg University Medical Center Mainz, \\ Mainz, Germany
}

\section{Key Words}

Intrauterine tracheal balloon occlusion .

Congenital diaphragmatic hernia · Fetoscopy •

Real-time 3-dimensional ultrasound

\begin{abstract}
Objective: The most common complication of intrauterine tracheal balloon occlusion is the preterm premature rupture of membranes (PPROM) which increases the rate of neonatal morbidity and mortality. Ultrathin fetoscopy may be a method of reducing the risk of PPROM. Materials and Methods: The operation was performed at the 27th week of gestation after sedation and relaxation of a fetus with bilateral congenital diaphragmatic hernia and with the liver lifted upwards into the thorax. An ultrathin sheath with a 1.2- $\mathrm{mm}$ fetoscope was used under real-time 3-D ultrasound guidance. The patient delivered in the 38th week of gestation and did not display PPROM after surgery until delivery. Conclusion: Fetal tracheal occlusion using ultrathin fetoscopic equipment in combination with real-time 3-D ultrasound may reduce the risk of PPROM.

Copyright $\odot 2009$ S. Karger AG, Base
\end{abstract}

\section{Introduction}

Sporadically occurring congenital diaphragmatic hernia $(\mathrm{CDH})$ has an incidence of $1-2$ in 5,000 newborns, depending on whether or not stillbirths are included $[1$, 2]. The best indicator and prognostic predictor for outcome and survival is the lung area to head circumference ratio (LHR). For measurement of the LHR, ultrasound is used to compare the proportion of the lung in the detected case with the lung proportion of normal fetuses at the same stage of gestation. The survival rate depends upon the development of the lung and the position of the liver. Bilateral $\mathrm{CDH}$ is mostly associated with a lethal prognosis.

One of the most common complications of intrauterine, minimally invasive fetal surgery is the causation of preterm premature rupture of membranes (PPROM; i.e. rupture of membranes before the 37 th week of gestation). The neonatal morbidity and mortality is, amongst other methods, ascertained by the loss of amniotic fluid caused by PPROM.

The data in the literature related to PPROM differ after amniocentesis and fetoscopic tracheal occlusion (FETO). The results of leading medical centers having significant experience with FETO show a high rate of PPROM after intrauterine fetal surgery using a 3-mm sheath [3-6].

\section{KARGER \\ Fax +4161306 1234 E-Mail karger@karger.ch} www.karger.com
Univ.-Prof. Dr. Michael Tchirikov

Department of Obstetrics and Fetal Medicine

Johannes Gutenberg University Medical Center Mainz

Langenbeckstrasse 1, DE-55101 Mainz (Germany)

Tel. +49 6131173 291, Fax +49 6131175 581, E-Mail tchirikov@uni-mainz.de 


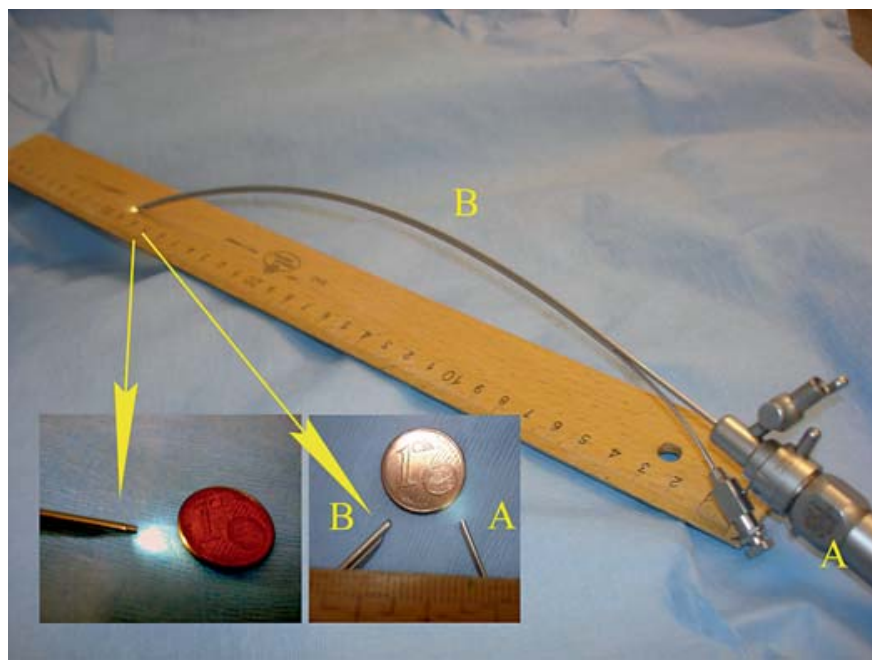

Fig. 1. A 1.2-mm 0-degree fetoscope with an ultrathin sheath. Fetoscope $11530 \mathrm{AA}, 0^{\circ}$, Karl Storz, Tuttlingen, Germany (A) and sheath 11530 KB, Karl Storz (B). The sheath was manually bent for tracheal intubation. The yellow arrows point to the sheath. To reduce the risk of fetal damage we ground and polished the tip of the sheath.

The aim of prenatal intervention is to influence the growth and development of the fetal lung. It can be achieved by fetoscopic tracheal balloon occlusion. Therefore, a small balloon is percutaneously inserted into the fetal trachea between the 26th and the 28th week of gestation. The fluid which is normally produced by the fetal lung cannot pass the closed trachea and thus leads to an expansion of the lung. The balloon must be removed before delivery and the the newborn is to be ventilated, resulting in a significant increase in the rate of survival $[4,7]$.

We hypothesize that one of the main risk factors of PPROM may be the thickness of the instrument used.

The following case highlights the successful combined use of an ultrathin sheath and a 1.2-mm fetoscope with real-time 3-D ultrasound to reduce the risk of PPROM with the consequence of reducing prematurity as well as neonatal morbidity and mortality.

\section{Case Report}

\section{Operating Procedure}

Based on the experience with experimental tracheal occlusion (TO) that we have performed in 17 fetal sheep of mid-gestational age, I here present a case of TO using ultrathin fetoscopic instruments.

FETO Using Ultrathin Fetoscopic

Equipment

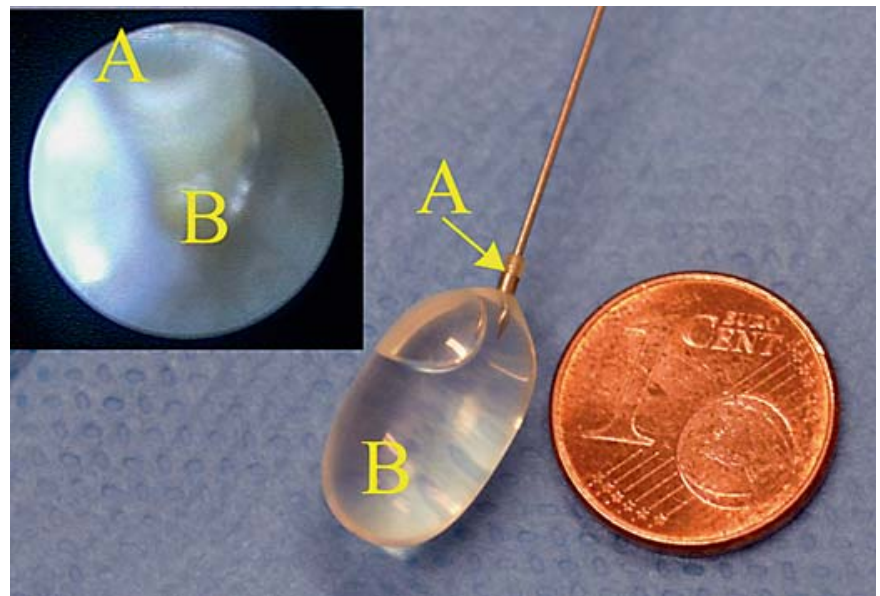

Fig. 2. Inflated balloon in fetal trachea (inset). $A=$ Valve of the balloon; B = inflated balloon.

This is the first surgical procedure performed worldwide in which fetoscopic tracheal balloon occlusion was combined with a real-time 3-D ultrasound probe (3.5 MHz, X-plane mode, Philips iU22, Philips Medical, Hamburg, Germany), thereby minimizing the diameter of the normal 3.0- to $4.0-\mathrm{mm}$ fetoscopic sheath by more than half. The standard fetoscopic sheath for TO has 3 channels: one channel for the 2-mm optic, one for the balloon catheter, and a small 1-mm channel for the saline infusion. The method of TO was improved using an ultrathin sheath with only 2 channels: a 1.2-mm channel for the optic and a small 1-mm channel for the saline infusion (11530 KB, Karl Storz, Tuttlingen, Germany) (fig. 1).

The operation was performed at the 27 th week of gestation on a fetus with bilateral CDH and with the liver lifted upwards into the thorax. The LHR was 0.7 and the MRI showed an estimated lung volume of only about $15 \%$ of the normal value. The fetus received $0.1 \mathrm{mg}$ vecuronium (Norcuron ${ }^{\circledR}$ ) and $0.01 \mathrm{mg}$ atropine and $1 \mu \mathrm{g}$ Fentanyl ${ }^{\circledR}$ by intramuscular injection under ultrasound guidance. After that, a fetoscope (11530 AA, $0^{\circ}$, Karl Storz) with a diameter of $1.2 \mathrm{~mm}$ was percutaneously inserted through the fetoscopic sheath (fig. 1) into the uterus with a posterior placenta under local anesthesia $\left(20 \mathrm{ml}\right.$ Xylocain $\left.{ }^{\circledR} 1 \%\right)$. To reduce the wide movement of the fetoscope at the time of entering the trachea we carefully selected the insertion point under ultrasound control.

The fetus was intubated during the insufflation of Ringer's solution ${ }^{\circledR}$ and the endotracheal bifurcation was located. The light optic was removed from the sheath and the balloon (Goldbal4 ${ }^{\circledR}$, $1 \mathrm{ml}$, BALT Extrusion, Montmorency, France) was inserted with the help of a catheter under real-time 3-D ultrasound guidance. After placing the balloon above the endotracheal bifurcation, it 
was inflated with $1 \mathrm{ml}$ of sodium chloride and the catheter was removed. During the insertion and inflation of the balloon, the real-time 3-D ultrasound probe was used to control the surgical procedure. Thus, the placement of the balloon and the wellbeing of the fetus could be monitored.

The light optic was inserted through the fetoscope sheath to ensure the correct positioning of the balloon (fig. 2). The iatrogenic polyhydramnion was drained and the fetoscope was removed from the uterus. Afterwards, fetal Doppler ultrasound showed a positive fetal heartbeat.

The LHR was increased from 0.7 to 2 . The balloon was punctured and deflated with a 22-gauge needle under ultrasound guidance at $34+2$ weeks of gestation. The fetus spat the deflated balloon out, which was also detected by MRI. The patient delivered by cesarean section at $37+3$ weeks of gestation and did not display any signs of PPROM. Unfortunately, after delivery it emerged that the bilateral $\mathrm{CDH}$ was too severe and distinct so that it was not possible for pediatric surgeons to cover the defect, and the newborn died 12 days after delivery.

\section{Discussion}

Intrauterine fetal tracheal balloon occlusion seems to improve the neonatal outcome of fetuses with right-sided $\mathrm{CDH}$ and a poor prognosis based on an LHR $<1.0$ and the liver lifted upwards into the thorax [4, 7]. The most common complication of this operation is that fetoscopic instruments with a diameter of $3.0-4.0 \mathrm{~mm}$ can induce PPROM, which significantly increases the rate of neonatal morbidity and mortality [4-7]. Harrison et al. [3] documented a rate of PPROM after FETO of $100 \%$ at a gestational age of less than 34 weeks. Deprest et al. [4] report a prevalence of PPROM in 35\% of patients at a gestational age of less than 32 weeks and in $50 \%$ of patients at a gestational age of less than 34 weeks, respectively. In 2006, they were also able to document additional data about PPROM, showing a prevalence of $16.7 \%$ in patients with a gestational age of less than 28 weeks and of $33.3 \%$ in those aged less than 32 weeks, respectively, whereas Jani et al. [6] and Deprest et al. [7] denote a PPROM rate of $57.1 \%$ after FETO.

The direct dependence of the PPROM rate on the diameter of amniotic membrane damage after the invasive procedure is obvious. For example, amniocentesis normally accomplished at the 16th week of gestation, using a needle with a $0.7-\mathrm{mm}$ diameter, shows rates of spontaneous PPROM after the procedure of less than $1 \%$ [8]. The risk of PPROM after amniocentesis using very thin needles $(0.34 \mathrm{~mm})$ is lower than $0.2 \%$ [pers. experience]. The degree of damage to the amniotic membrane seems to influence the rate of PPROM not only after AC but also after fetoscopy.
To reduce the risk of PPROM we successfully combined minimized instruments with an ultrathin sheath and a fetoscope of $1.2 \mathrm{~mm}$ in diameter for FETO using real-time 3-D ultrasound guidance. Firstly, the TO involves tracheal intubation. The careful choice of the fetoscope's insertion point under ultrasound control helped to reduce the wide shift of the fetoscope's position at the time of entering the trachea. The use of thin instruments limits the possibility of the head position being changed by the fetus moving the fetoscope. On the other hand, the risk of tracheal perforation could be increased. To reduce the risk of fetal damage, we modified the tip of the sheath by grinding and polishing the tip (fig. 1). However, forcing the fetus into a hyperextended position with the thin fetoscope, which exerts pressure on the lip-palate-upper maxilla and on the epiglottis, could lead to fetal damage. In our opinion, the decision of using a very thin sheath for TO must be individually discussed, especially if the fetus is poorly positioned for percutaneous intubation.

We used real-time 3-D ultrasound with an X-plane probe to portray the catheter in two planes because we did not use a fetoscopic optic during the part of TO operation when the balloon catheter is introduced into the fetal trachea.

\section{Conclusion}

Fetal TO using ultrathin fetoscopic equipment in combination with real-time 3-D ultrasound may reduce the risk of PPROM. The dimension of damage to the amniotic membrane likely influences the rate of PPROM after the fetoscopic surgical procedure.

\section{Acknowledgements}

I thank Karl Storz, Tuttlingen, Germany, for supporting the surgical procedure, and Philips Medical, Hamburg, Germany, for providing the ultrasound system. I am grateful to Dr. Miriam Strohner, University of Mainz, Germany, for her help with this case study. Many thanks are due to Prof. Dr. Steven Johnsen, University of Göttingen, Germany, for his help with the manuscript. 


\section{References}

-1 Skari H, Bjornland K, Haugen G, Egeland T, Emblem R: Congenital diaphragmatic hernia: a meta-analysis of mortality factors. J Pediatr Surg 2000;35:1187-1197.

$\checkmark 2$ Rottier R, Tibboel D: Fetal lung and diaphragm development in congenital diaphragmatic hernia. Semin Perinatol 2005; 29:86-93.

>3 Harrison MR, Keller RL, Hawgood SB, Kitterman JA, Sandberg PL, Farmer DL, Lee H, Filly RA, Farrell JA, Albanese CT: A randomized trial of fetal endoscopic tracheal occlusion for severe fetal congenital diaphragmatic hernia. N Engl J Med 2003;349: 1916-1924.
4 Deprest J, Jani J, Gratacos E, Vandecruys H, Naulaers G, Delgado J, Greenough A, Nicolaides K, FETO Task Group: Fetal intervention for congenital diaphragmatic hernia: the European experience. Semin Perinatol 2005;29:94-103.

5 Deprest J, Jani J, van Schoubroeck D, Cannie M, Gallot D, Dymarkowski S, Fryns JP, Naulaers G, Gratacos E, Nicolaides K: Current consequences of prenatal diagnosis of congenital diaphragmatic hernia. J Pediatr Surg 2006;41:423-430.

-6 Jani JC, Nicolaides KH, Gratacós E, Vandecruys H, Deprest JA, FETO Task Group: Fetal lung-to-head ratio in the prediction of survival in severe left-sided diaphragmatic hernia treated by fetal endoscopic tracheal occlusion (FETO). Am J Obstet Gynecol 2006;195:1646-1650.
7 Deprest J, Jani J, Lewi L, Ochsenbein-Kölble N, Cannie M, Doné E, Roubliova X, Van Mieghem T, Debeer A, Debuck F, Sbragia L, Toelen J, Devlieger R, Lewi P, Van de Velde M: Fetoscopic surgery: encouraged by clinical experience and boosted by instrument innovation. Semin Fetal Neonatal Med 2006; 11:398-412.

8 Deprest J, Lewi L, Devlieger R, de Catte L, Hoylaerts M, Ochsenbein-Kölble N, Bilic G, Zisch A, Zimmermann R: Enrichment of collagen plugs with platelets and amniotic fluid cells increases cell proliferation in sealed iatrogenic membrane defects in the foetal rabbit model (authors' reply). Prenat Diagn 2008;28:878-880. 